\title{
A computational electoral competition model with social clustering and endogenous interest groups as information brokers*
}

\author{
Vjollca Sadirajł Jan Tuinstra ${ }^{\ddagger}$ and Frans van Winden ${ }^{\S}$
}

July 2004

\begin{abstract}
We extend the basic model of spatial competition in two directions. First, political parties and voters do not have complete information but behave adaptively. Political parties use polls to search for policy platforms that maximize the probability of winning an election and the voting decision of voters is influenced by social interaction. Second, we allow for the emergence of interest groups. These interest groups transmit information about voter preferences to the political parties, and they coordinate voting behavior. We use simulation methods to investigate the convergence properties of this model. We find that the introduction of social dynamics and interest groups increases the separation between parties platforms, prohibits convergence to the center of the distribution of voter preferences, and increases the size of the winning set.
\end{abstract}

KEYWORDS: Computational political economy, social dynamics, interest groups, spatial competition, polling, campaign contributions.

JEL CLASSifiCATiOn: D72, D83

*A previous version of this paper, entitled "Interest Groups and Social Dynamics in a Model of Spatial Competition", was presented at the Public Choice Society meetings, March 2000, Charleston, South Carolina, U.S., at the 7th Viennese Workshop on Optimal Control, Nonlinear Dynamics and Dynamic Games, May 2000, Vienna, Austria and at the Computational Economics Conference, July, 2000, Barcelona, Spain. Comments by Arno Riedl and Randolph Sloof are gratefully acknowledged.

$\dagger$ University of Arizona, 401 McClelland Hall, P.O. Box 210108, Tucson, Arizona 85721-0108 USA. E-mail: vsadiraj@econlab.arizona.edu.

${ }^{\ddagger}$ CeNDEF and Department of Quantitative Economics, University of Amsterdam, Roetersstraat 11, 1018 WB Amsterdam, the Netherlands, E-mail: j.tuinstra@uva.nl.

${ }^{\S}$ CREED and Department of Economics, University of Amsterdam, Roetersstraat 11, 1018 WB Amsterdam, the Netherlands, E-mail: f.a.a.m.vanwinden@.uva.nl. 


\section{Introduction}

Models of electoral competition typically make extremely strong informational assumptions regarding the political preferences of voters. In Downs-Hotelling spatial competition models political parties or candidates are generally assumed to have complete information about the distribution of the ideal policies of the voters when selecting platforms. Probabilistic voting models relax only somewhat this assumption of complete information on the side of parties by introducing a 'bias' term in the preferences (utility function) of voters, which favors one of the parties independent of their policy stances. However, parties are supposed to exactly know the probability distribution of these biases. Another strand of models, focusing on campaign contributions and expenditures, allows for malleable preferences but assumes that parties know precisely how campaign expenditures affect those preferences. ${ }^{1}$ Although we certainly do not want to argue against the use of simplifying assumptions, we think it is important to also examine models that make more realistic assumptions. For instance, how do parties actually get their information regarding voter preferences?

Starting point of this paper is the observation that parties do not just know what makes voters tick but have to find out through some kind of polling. Taking the two-party spatial competition model as framework, we therefore incorporate polls as a carrier of information on political preferences. However, polling is a costly search activity. Parties require resources to do so. For two reasons, voters may be willing to contribute in the form of effort or money. Firstly, because in this way they can affect the election outcome (electoral motive). Secondly, by conditioning their contributions they may affect the policies of parties (influence motive). Conditioning takes place by making contributions only available for polling on issues that are salient to the contributing voters. To illustrate the realism of this assumption, we refer to the U.S. presidential elections. As exemplified by Howard Dean's campaign, voters contribute to (new) candidates within parties who are willing to represent their major concerns. This effectively implies that the amount of polling regarding policy stances related to these concerns is increased. If the candidate is successful (s)he will win the race and can implement the policies preferred by the voters who supported this candidate. Instead of contributing directly to candidates or parties, voters may choose an indirect way by supporting intermediary institutions with the same purpose (see, e.g., www.meetup.com). For simplicity, we will not distinguish between these different channels of political influence, but have voters contribute to an interest group which makes their contributions conditionally available to the parties. In line with the evidence presented by Ansolobehere et al. (2002), contributions are not modeled as resulting from an explicit investment calculus, but are assumed to be primarily driven by dissatisfaction with existing policies on issues of particular concern to the voter. Furthermore, voters who get politically involved in this way are likely to identify themselves with the political issues and interest groups they go for

\footnotetext{
${ }^{1}$ See e.g. Mueller (2003).
} 
(Akerlof and Kranton (2000)). Our model assumes, therefore, that some coordination of voting will take place, because of the extra weight that voters will attach to the policy positions identified with the interest groups. Clearly, this coordination of voting may in turn affect policies.

By having political parties experiment before an election with different policy positions to improve their chances of winning, our model is most directly related to the work of Kollman et al. $(1992,1998)$, who introduced this notion of adaptive political parties. $^{2}$ An important motivation for their research was to investigate the relevance of the theoretical 'chaos' results for multi-dimensional issue spaces. These results suggest that, in general, incumbents would always be defeated by the challenging party, and that policies would wander all over the issue space (for surveys, see Coughlin (1990), Mueller (2003)). In contrast, the simulations of Kollman et al. (1992) showed convergence of the parties' platforms to the center of the distribution of voters' ideal positions. Our paper extends their analysis, and the existing literature on electoral competition and interest groups, in two directions.

The first direction our analysis takes has the following features: (a) we allow interest groups of voters to develop, where the contributions of the latter determine the resources an interest group can offer parties; (b) these resources provide endogenous war-chests to party candidates for campaigning, with polling results determining the party's platform; (c) resources for polling provide endogenous opportunities and constraints for the transfer of information between voters and parties. Moreover, interest groups coordinate the voting behavior of their members through identification.

The second direction explored in this study concerns the impact of endogenously changing political preferences of voters. Even if voters are fully aware of the platforms selected by parties, they will often lack the expertise necessary to evaluate the consequences of these platforms for their concerns, and they may not be willing to bear the costs of finding out. Instead, they may take cues from the positions taken by parties (Jackson (2003)), the endorsements by interest groups (Grossman and Helpman (1999)), or the political preferences of other voters they meet. In this paper, we will focus on the last possibility, assuming that preferences are influenced through social interaction, that is, the distribution of beliefs among the voters interacted with. As a result, clustering of voters' ideal policies can occur. Our work on this issue of social clustering is related to models of herding behavior (Banerjee (1992), Bikhchandani et al. (1993), Kirman (1993)) and, more directly, to the psychological social impact model of Latane (1981) and the opinion formation model of Corradi and Ianni (1998).

This paper is mainly concerned with the role of interest groups as information brokers in a spatial competition model, acknowledging that political agents face substantial information problems in reality. In the full model, with endogenous political preferences, the importance of the interest groups depends on the interaction structure within the electorate and on the election outcomes, while the latter are again influenced by the sizes and political stances of the interest groups. Among the ques-

\footnotetext{
${ }^{2}$ See also De Marchi (2003).
} 
tions that will be addressed are the following: Does the structure provided by interest groups help stabilize the political process, or do we witness more volatility in the presence of these groups? What are the welfare effects of interest groups performing the role of information brokers? What are the consequences of political preferences affected by social interaction? Does social interaction lead to consensus? How do interest groups impact the belief formation process and, thereby, the results of the full model? Because of the complexity of the theoretical model, simulation methods will be used to explore the behavioral dynamics and tendencies, and to derive directions for future research.

The rest of the paper is organized as follows. Section 2 presents our basic electoral competition model, where parties have to engage in costly search to find out about voter preferences. In Section 3, we extend this model with endogenous interest group formation, to investigate the role and influence of interest groups as information brokers. Section 4 studies how clustering of political preferences may arise through social interaction and the electoral consequences thereof. Section 5 investigates the dynamics of the full model, comprising interest groups as well as political preference formation, while Section 6 concludes.

\section{Electoral competition with information search}

Let there be a population of $N$ voters, indexed $j=1, \ldots, N$ and let there be $I$ issues, indexed $i=1, \ldots, I$. For issue $i$ there are $K_{i}$ different positions, indexed $k=1, \ldots, K_{i}$. The policy or issue space is $X=\left\{1, \ldots, K_{1}\right\} \times \ldots \times\left\{1, \ldots, K_{I}\right\}$. Voters are associated with an ideal point $\mathbf{x} \in X$ and their utility with respect to a certain policy outcome $\mathbf{y} \in X$ is given by the negative of the (weighted) Euclidean distance between this policy outcome and their ideal point, i.e. utility for voter $j$ of policy outcome $\mathbf{y}$ is given by

$$
u_{j}(\mathbf{y})=-\sum_{i=1}^{I} s_{j i}\left(x_{j i}-y_{i}\right)^{2},
$$

where $s_{j i} \in S=\left\{s^{1}, s^{2}, \ldots, s^{L}\right\}$ is nonnegative and corresponds to the weight or strength that voter $j$ attaches to issue $i$. Each voter $j$ is therefore identified by a $2 I$-tuple $\left(x_{j}, s_{j}\right)=\left(x_{j 1} \ldots, x_{j I}, s_{j 1}, \ldots, s_{j I}\right) \in X \times S^{I}$. If a voter can choose between two different political candidates ( $\mathrm{s}$ )he votes for the candidate which has a platform that generates the highest utility for him (her).

A configuration of voters is generated as follows. First, for each voter $j$, an ideal point $\left(x_{j i}\right)_{i \in I}$ is generated by independently drawing $x_{j i}, i=1, \ldots, I$, from the discrete uniform distribution on $\left\{1,2, \ldots, K_{i}\right\}$. Subsequently, the strengths for agent $j$ on issue $i\left(s_{j i}\right)$ are independently drawn from a discrete distribution on $S$.

Given the initial configuration of voters an electoral landscape is constructed as follows. There are two political parties entering the election, the incumbent and the 
challenger. In line with Kollman et al. $(1992,1998)$, who were the first to study this type of computational electoral competition model, we assume that the incumbent does not change its policy from the previous period. Each voter votes for the political candidate yielding him the highest utility as given by (1). In case this utility is the same for both political candidates the voter votes with probability 0.5 for the challenger and with probability 0.5 for the incumbent. For every position $z$ in the issue space the height of the electoral landscape can now be determined as the expected fraction of voters voting for the challenger, if it selects position $z$. At every position where the height of the landscape is above 0.5 the challenger is expected to win the election.

Political parties are assumed to be only interested in getting elected, i.e., they view policies as a means to winning elections. The objective of the challenger is therefore to find the positions of the high points of the landscape. This is consistent with a situation where candidates are only interested in getting elected and therefore search for the highest position (which will make them harder to beat in the next election if they win the present one). It is also consistent with a situation where candidates are interested in maximizing the number of seats in the legislature. The problem of the challenger therefore reduces to a search problem: it has to find the optimum of some complicated nonlinear function (i.e. the electoral landscape). We assume that the challenger applies random search, that is, the challenger randomly selects a number of positions in the issue space and tests them against the incumbent's policy using a poll. Such a poll consists of a randomly drawn subsample of the population of voters. The challenger observes the fraction of the poll that favors its policy over the incumbent's policy and uses this as an estimate for the true height of the landscape at that position. ${ }^{3}$ If there are platforms with a polling result of at least 0.5 then the challenger chooses the position with the highest polling result, otherwise it chooses the incumbent position. Subsequently, the election takes place and the candidate that wins will be the incumbent for the next period. This procedure is repeated for each election that follows.

Let us now discuss some simulations with this basic model. For all simulations in this paper we use the following specification of the model. We have two issues $(I=2)$, with 5 positions per issue $\left(K_{1}=K_{2}=5\right)$ and three different strengths per issue, characterizing indifference, moderate importance and high importance attached to an issue $(S=\{0,0.5,1\})$. Furthermore, we consider 20 consecutive elections and work with a population of $N=301$ voters. For each poll $10 \%$ of the population is sampled. The choice to consider only two issues is less restrictive than it might seem. There is some empirical evidence that politics takes place in a low-dimensional space

\footnotetext{
${ }^{3}$ The fraction of voters in the poll who favor the challenger at a certain position is a reasonable estimator for the altitude of the electoral landscape at that position. Let the altitude of the electoral landscape at a certain position be $p$. Then randomly drawing (without replacement) $n$ voters out of the population of $N$ voters, the fraction of voters in the poll who favor the challenger has mean $p$ and variance $\frac{N-n}{N-1} \frac{p(1-p)}{n}$ (see e.g. Ross (1993, p.52)).
} 

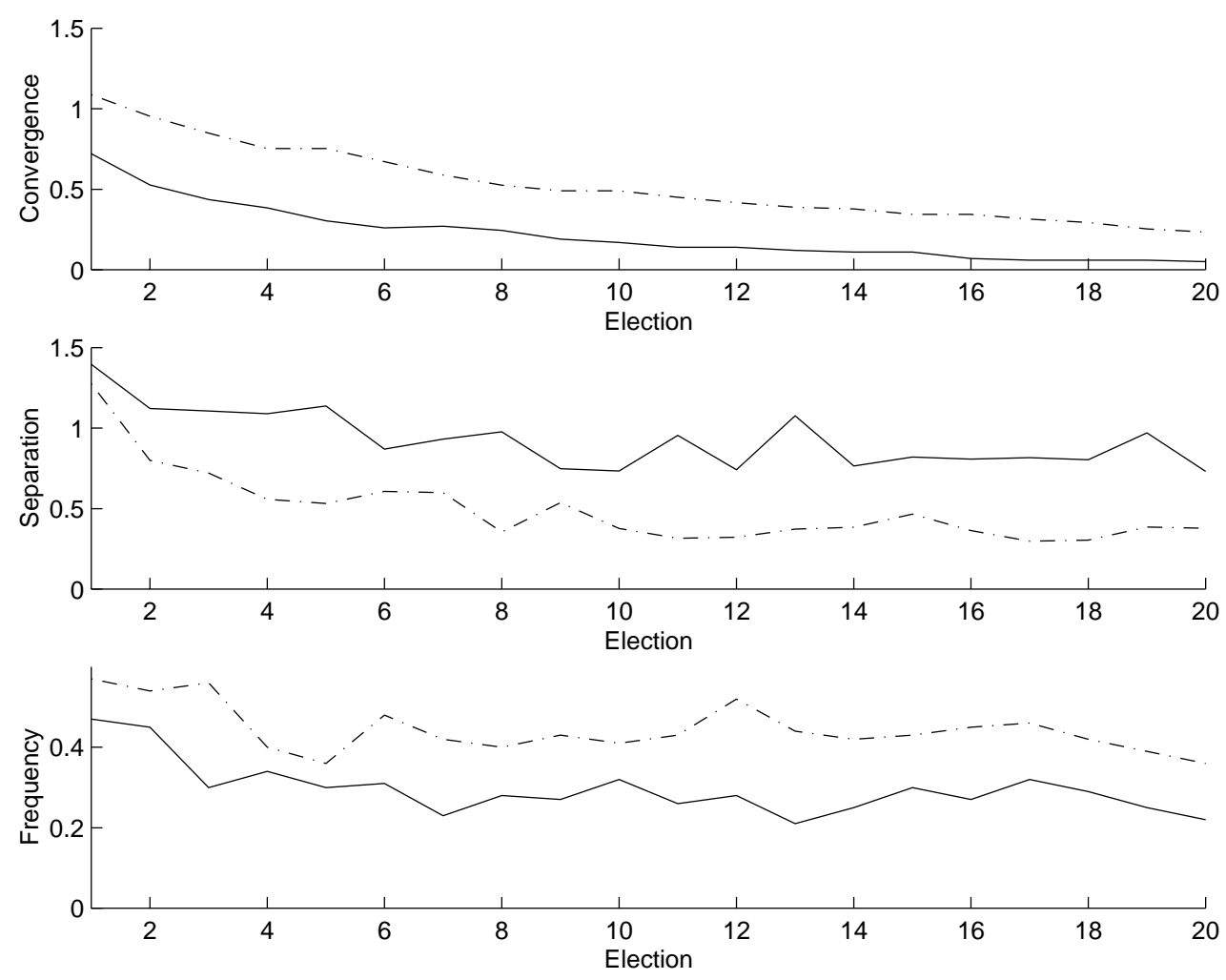

Figure 1: Time series of different measures, averaged over 100 trials, for the benchmark model. Solid lines correspond to the model with 8 polls, broken lines correspond to 2 polls. Upper panel: average Euclidean distance between center and election outcome. Middle panel: average Euclidean distance between challenger and incumbent. Lower panel: frequencies with which the challenger wins an election.

(see e.g. Poole and Rosenthal (1991), who show that at most two dimensions are necessary to explain the roll call voting behavior of members of Congress in the US).

Figure 1 shows the value of three different measures describing the outcomes of the model averaged over 100 trials. For each trial a new configuration of voters is drawn. There are 20 elections with either 2 (broken lines) or 8 (solid lines) polls per election. The first measure ('convergence', upper panel in Figure 1) corresponds to the Euclidean distance between the election outcome (that is, the policy position of the candidate that wins the election) and the center of the distribution of voter preferences. In this paper we refer to the center as the policy position that is constructed in the following way. For each issue we consider the distribution of ideal points in that issue and determine the (uni-dimensional) median voter in that issue. We then define the center of the whole issue space as that (multi-dimensional) policy position for which each element corresponds to the uni-dimensional median in the 
corresponding issue. The upper panel of Figure 1 shows that the distance between the election outcome and this center position decreases over time towards 0 , implying that in some sense a median-voter result still applies in our model. Furthermore, more information about the electoral landscape (i.e. an increase in the number of polls), leads to faster convergence. The second measure ('separation', middle panel of Figure 1) gives the Euclidean distance between the policy positions of the incumbent and the challenger at each election. The simulations show that the separation between parties' platforms decreases as elections go by. However, running more polls generates a higher separation. The reason is that an increase in the number of polls increases the probability of selecting positions that are close to the incumbent position. For such positions the polling result may be (due to sampling errors) such that the challenger selects this neighboring position although it would have been better off taking the incumbent's position. This leads to a higher average separation. This also suggests that the challenger's probability of winning may be reduced if he runs more polls. The lower panel of Figure 1, which shows the empirical frequency of election victories of the challenger, confirms this. Of course, the simple assumption that the challenger is not restricted in its mobility, like for instance to a region near its previous position (as in Kollman et al. (1992)), is important here. However, we do not want to investigate more specific assumptions in this respect, because of our interest in comparative issues, that is, the consequences of introducing interest groups and social clustering. Summarizing Figure 1, the simulation results for the basic model replicate the finding of Kollman et al. (1992) that policy platforms tend to converge to the center of the distribution of voter preferences.

\section{$3 \quad$ Interest groups as information brokers}

In the realistic situation modeled in the previous section where political parties have by themselves little information about the preferences of the voters, there exists a natural role for interest groups to emerge as information brokers. In fact, by participating in collective action concerning issues that are important to them, voters can influence the electoral process in three different ways. First, by joining in the supply of resources (monetary contributions or effort) to a political party they can influence that party's electoral success, given that polling is costly. Second, coordination creates the opportunity to gain influence through conditioning the polling carried out with the resources supplied. Third, identification with the interest group is likely to induce some coordination of voting behavior. By giving extra weight to the issue emphasized by the interest group, political preferences are effectively shaped into some kind of lexicographic order. Of course, since joining an interest group is assumed to entail some costly contribution, there is a free-riding problem to be taken care of. In light of existing empirical evidence, participation will not be modeled as the outcome of a sophisticated political investment calculus, but rather as a form of consumption (expression) and emotional gratification linked up with the hope of affecting the po- 
litical process in a desired direction (see e.g. Ansolobehere et al. (2002), Marcus and MacKuen (1993)). ${ }^{4}$

More formally, interest groups are modeled as follows. For convenience, interest groups are assumed to be organized around single issues. ${ }^{5}$ Interest group $m$ is denoted by $\left(i^{m}, k^{m}\right)$, where $i^{m} \in\{1,2, \ldots, I\}$ is the issue on which group $m$ focuses and $k^{m} \in\left\{1,2, \ldots, K_{i^{m}}\right\}$, is the (unique) position that this group takes on that issue. For example, the interest group characterized by $\left(i^{m}, k^{m}\right)=(2,5)$ takes position 5 on issue 2 . Notice that there are potentially $\sum_{i=1}^{I} K_{i}$ different interest groups. The potential members of group $m$ are those voters that have position $k^{m}$ on issue $i^{m}$. These potential members decide whether to join or not. After this process of interest group formation is over, it is endogenously determined which interest groups become 'effective', that is, which groups have collected enough resources to be able to support a candidate (assuming a minimal cost of polling).

We now turn to an individual's decision to join an interest group on a particular issue. Three factors are assumed to determine the benefits from joining: dissatisfaction with the incumbent's policy (with disappointment and anger as possible emotional urges), the importance attached to the issue concerned, and the present size of the interest group. Size is assumed to matter for two reasons. First, the larger the interest group, the higher the chances of having some influence. Second, the larger the interest group, the stronger the attraction to identify oneself with the group (bandwagon effect).

On the other hand, there are some costs of joining an interest group. First of all, joining implies that a contribution $c$ (in money or in kind) has to be paid. Moreover, as will become clearer below, joining implies some coordination of voting that may entail a utility loss regarding the issues that are not relevant to this interest group.

More specifically, the interest group formation process is modeled as follows. Voters are drawn in a random order to decide (sequentially) whether to join some interest groups or not. This procedure is repeated once, implying that each voter has to decide whether to join or not at most two times. Consider voter $j$, characterized by $\left(x_{j}, s_{j}\right)=\left(x_{j 1} \ldots, x_{j I}, s_{j 1}, \ldots, s_{j I}\right)$. There are $I$ potential interest groups the voter can join, one for each issue. For each relevant interest group $m$ the number $v_{j m}$, representing the benefits from joining, is determined as

$$
v_{j m}=V\left(\frac{n_{m}^{i g}}{N}, s_{j i^{m}},\left|k^{m}-y_{i^{m}}\right|\right),
$$

where $n_{m}^{i g}$ is the current number of members of interest group $m$ (which of course depends upon the decisions made by voters that decided prior to voter $j$ ) and where

\footnotetext{
${ }^{4}$ See also Camerer (2002) on the lack of sophistication observed in experimental studies of decision making in complex environments.

${ }^{5}$ An extension to multi-issue interest groups is however straightforward. Incidentally, an ideological political party, that is, a party that is concerned with policy outcomes, can in fact be interpreted as an interest group organized around multiple issues.
} 
$y_{i^{m}}$ is the incumbent's position on the interest group's issue. In line with the factors discussed above, $v_{j m}$ is assumed to be positively related to: the relative size of the interest group, the current distance between the voter (and therefore the interest group) and the incumbent on the issue relevant to this interest group, and the weight this voter attaches to this issue. ${ }^{6}$ Since for each interest group he joins the voter has to pay the contribution $c$, he ranks the different interest groups according to the values of the associated benefits $v_{j m}$. If the highest value of these benefits exceeds the contribution fee $c$, he joins the corresponding interest group and if it does not, he joins no interest groups at all. If the first interest group is joined the voter considers the next interest group in the ranking. If its benefits exceed the contribution fee $c$ the voter also joins this interest group, and so on.

In our model interest groups influence the election process, on the one hand, by coordinating the voting behavior of their members and, on the other hand, by the role they play in the transmission of information about the electoral landscape. We first discuss the latter. Each interest group possesses certain resources raised by the contributions of its members. These resources are offered to the challenger on two conditions: $i$ ) resources are used for running polls in policy positions coinciding with the interest group's position on the relevant issue; ii) from among the policy positions tested by the challenger, the platform with the highest poll result is selected (provided this platform is preffered over the incumbent's position, that is, the estimated height of the electoral landscape at that position should be higher than or equal to 0.5). An interesting interpretation of the above procedure is the following. Within the challenging party, different candidates compete for becoming the actual challenger of the current incumbent. The party itself comes up with some candidates but the interest groups can also support some candidates. The relative polling successes of the different candidates then decide which candidate becomes the actual challenger (as in case of a primary). The number of polls to be ran is determined by the resources offered by the interest groups and the cost of running a poll. ${ }^{7}$ This endogenously determines which interest groups become effective, all other interest groups remain passive and play no further role in the election process.

The voting behavior of the effective interest groups' members is coordinated as follows. Once the two political candidates are known each effective interest group decides which party to support and then all members of the interest group vote for

${ }^{6}$ For our simulations the function $V$ is specified as

$$
v_{j m}=s_{j i^{m}}\left(y_{i^{m}}-k^{m}\right)^{2} \exp \left(1+\frac{n_{m}^{i g}}{N}\right) .
$$

Notice that voters with $s_{j i^{m}}=0$ never join. Also observe that in order to get an interest group started at a distance $d$ from the incumbent the contribution $c$ should not exceed $d^{2} \exp (1)$ (recall that the interest group formation process starts out with $n_{m}^{i g}=0$, and that $\left.s_{j i} \leq 1\right)$. In our simulations we take $c=1.4<\exp (1)$, hence allowing interest groups to emerge anywhere (except, of course, at the incumbent's position for that issue).

${ }^{7}$ In the simulations the cost of running a poll is taken to be equal to 50 . 
that party (if a voter is a member of more than one effective interest group that support different candidates, (s)he aligns with the interest group that produced the highest benefit $v_{j m}$ ). The decision which party to support is taken in the following way. If exactly one of the candidates takes the interest group's position on the relevant issue, the interest group supports that party. If one candidate is closer to the interest group's position than the other candidate, the former is supported. If both candidates have the same position as the interest group, or the distance from the interest group's position on the relevant issue is the same, the interest group members vote according to the utility given by (1).

During an electoral campaign, apart from the platforms supported by interest groups, the challenger is assumed to run some independent polls on platforms selected randomly in the issue space. ${ }^{8}$ It then selects the policy position with the best polling result from among all the positions with an altitude of at least 0.5. If there are no such positions then the incumbent's position is selected. Voters organized in interest groups vote as discussed above. All other voters vote according to the weighted Euclidean distance between their ideal points and the different policy positions, in line with (1). The party with the majority of votes wins the election.

Before we study some simulations let us try to develop an intuition for what might happen. We have a population of voters with separable and symmetric preferences, uniformly distributed over the issue space and therefore we expect the generalized median voter to exist. The Generalized Median Voter Theorem (see Hinich and Munger (1997)) says that, once the median is located, no other platform can defeat it. It has already been argued in Section 2 that because the probability of choosing any point in the space (the median in particular) is strictly positive, in the limit the median is located with probability 1 . Due to the finiteness of our issue space this happens in finite time. Hence, the model predicts that in the long-run the incumbent converges to the median. Now consider what happens when we introduce interest groups. Notice that for any voter, membership of interest group $m$ is partly equivalent with changing the structure of preferences. More explicitly, instead of corresponding to weighted Euclidean distance, preferences become, in some sense, lexicographic: weighted Euclidean distance only becomes important when the interest group's issue is indecisive. As we will show later (Section 5), an important consequence of this is that the set of policy platforms defeating the incumbent's position (the winning set) is expanded. This is due to the fact that interest groups are more likely to form far away from the incumbent and hence tilt the electoral landscape at the expense of the incumbent. This leads to a higher probability for the challenger to win an election. Furthermore, the probability that the median is located at a given election, is higher for the model with interest groups as compared to the basic model. If an interest group emerges at a (uni-dimensional) median position, polls facilitated by such an interest group have a much higher probability of locating the (multi-

\footnotetext{
${ }^{8}$ In the simulations, the challenger runs 2 independent polls, each again consisting of a randomly drawn sample of $10 \%$ of the population.
} 

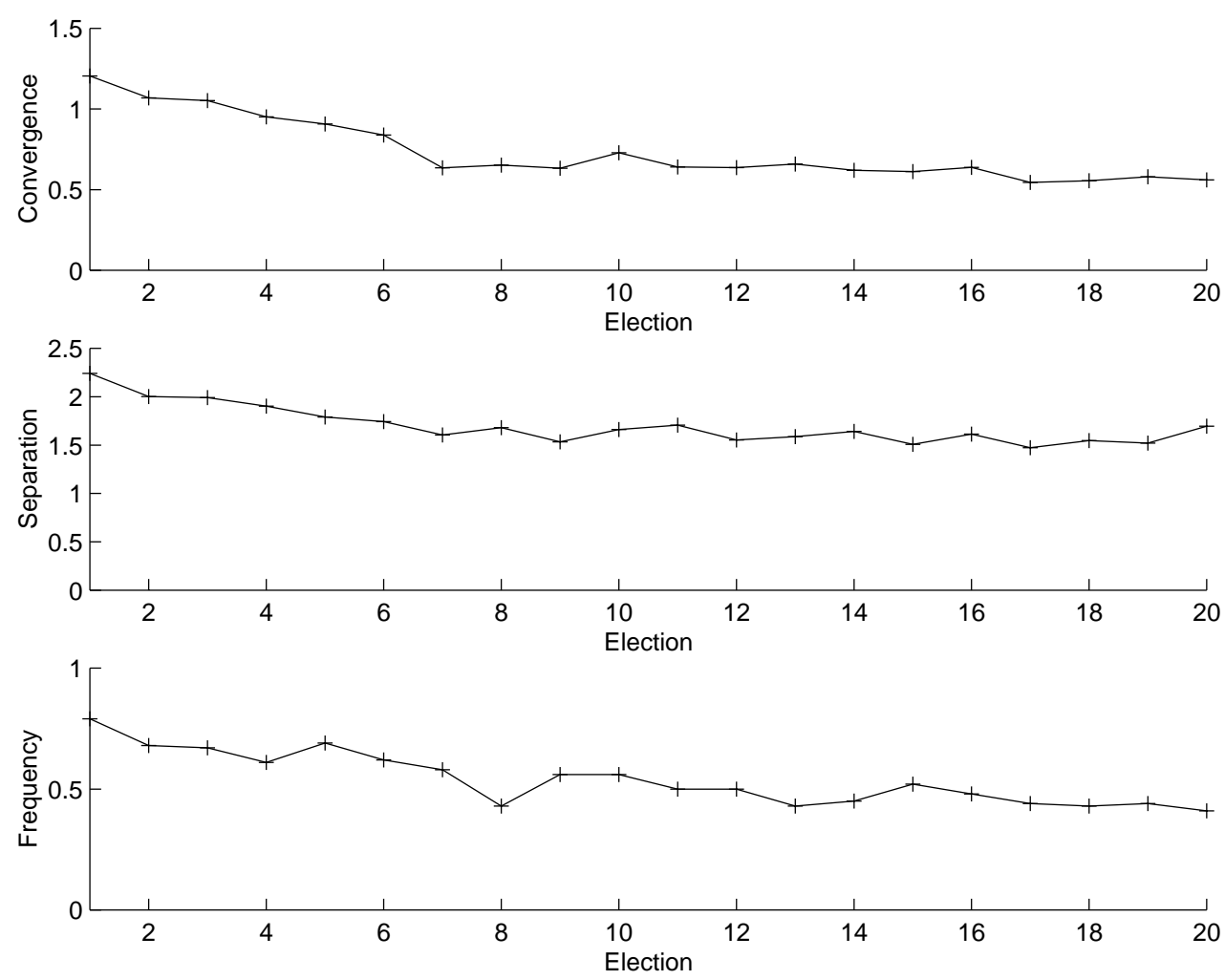

Figure 2: Time series of different measures, averaged over 100 trials, for the interest group model. Upper panel: average Euclidean distance between center and election outcome. Middle panel: average Euclidean distance between challenger and incumbent. Lower panel: frequencies with which the challenger wins an election.

dimensional) median $\left(1 / K_{i}\right.$ versus $1 /\left(K_{1} \times \ldots \times K_{I}\right)$ for a regular poll $)$. Thus, if the location of the incumbent favors the organization of the median voters, the median is located much faster than in the basic model of Section 2. On the other hand, if the distribution of voters allows for formation of interest groups asymmetric to the median the electoral system can move away from the median and cycles in winning platforms may appear. ${ }^{9}$ To illustrate this point consider the case where, once the incumbent is at the median, two groups located on different issues and different from the median organize in interest groups. Then the policy position corresponding to the intersection may, for certain stochastic realizations of voter preferences, defeat

\footnotetext{
${ }^{9}$ Sadiraj et al. (2004a) consider a framework, with two sectors and a government that uses taxes to redistribute income between sectors, in which this mechanism (which stems from the fact that interest group formation is advanced by dissatisfaction with the current government policy) is shown to be able to lead to ambiguous comparative statics results and cyclic behavior in interest group sizes and government policy.
} 


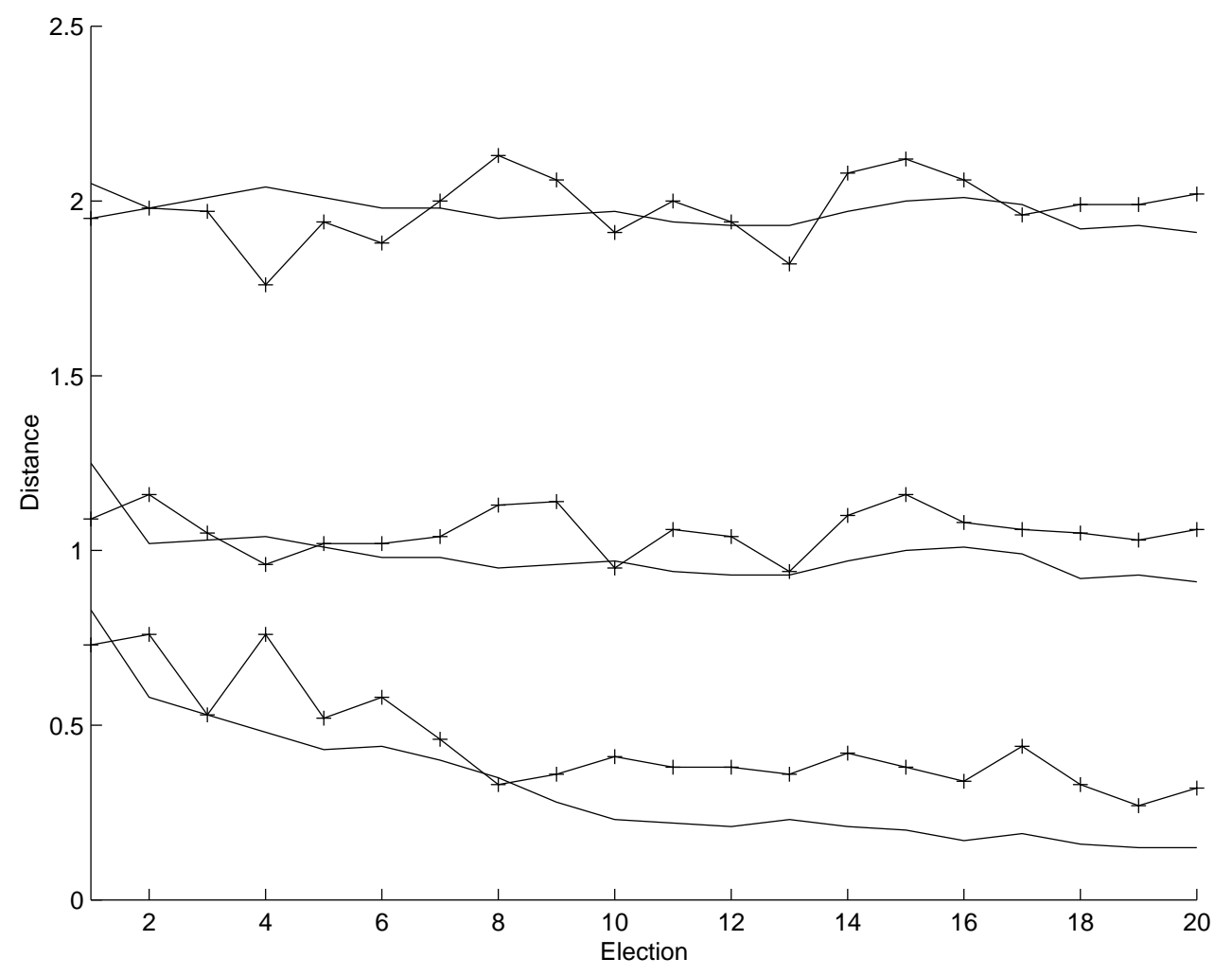

Figure 3: Time series of the distance (averaged over 100 trials) between interest groups' positions and the incumbent, for the benchmark model (solid lines) and the interest group model $(+)$.

the center, only due to the fact that interest groups coordinate voting behavior. The increase in the winning set results in a higher probability that the challenger wins the election.

Figure 2 shows some distance measures for the simulations we have run. As in the benchmark model both the distance between parties and the distance between the policy outcome and the center decrease over time. The most notable difference between the basic model and the model with interest groups is that the separation between party platforms for the latter is significantly higher, with no apparent convergence to the center. Also, the frequency with which the challenger wins the election shows that the existence of interest groups increases the probability of winning for the challenger. Summarizing, there are two main consequences of the presence of interest groups: i) an increase in the number of polls, and ii) an increase in the size of the winning set. The extra polls that the challenger can run, thanks to the interest groups, help this party to better explore the electoral landscape. This effect, combined with a larger set of platforms defeating the incumbent, increases the prob- 
ability the challenger wins an election. The fact as such that more polls can be run is not sufficient to produce this result, as shown by the simulation results of the basic model presented in Figure 1. In particular, it seems to be the increase in the winning set that significantly enhances the probability of winning. Note that, although the number of polls in the interest group model is variable (2 independent polls and a variable number of polls financed by interest groups), it is on average equal to 8 per election, facilitating comparisons with simulations of the benchmark model with 8 independent polls (i.e. the solid lines in Figure 1).

More results concerning the influence of interest groups on policy outcomes are presented in Figure 3. This figure shows for the basic model and for the model with interest groups, the distance between the policy outcome for the first issue and the positions 1, 2 and 3 on that issue, respectively. Clearly, the existence of interest groups leads to much more volatility in policy outcomes. In the absence of interest groups, the policy outcome seems to converge to the center of the issue space (the distance measure converges to 0,1 and 2, respectively), whereas for the model with interest groups this is not so clear-cut. This volatility is due to the fact that the larger interest groups tend to emerge at more extreme positions. As a consequence, voters at these positions are sometimes better off, and the convergence to the center seems to be broken. Note that we obtain these results even though the space is very small and hence the probability that the system settles at the center is high.

\section{Social dynamics}

In the previous section we have focused on the interaction between voters and political parties via interest groups as information brokers. In this section we explore an alternative informational issue, this time concerning the political preferences of voters and how these may be influenced through interaction between these voters. As observed by Grossman and Helpman (1999), even though voters may know the policy positions taken by political candidates, they may not fully comprehend how these policies would affect them personally. This realistic information problem translates into uncertainty on the side of voters as to what their ideal point is. One way to deal with this issue, explored by Grossman and Helpman, is to assume that interest group leaders have better information which they can signal to group members through endorsements. We will take a different route by investigating an opinion adaptation model in which the distribution of opinions perceived through interaction with other voters plays an important role. This interaction may lead to a clustering of opinions and, in the presence of interest groups, it may influence the interest group formation process.

Suppose we have created an initial configuration of the population of voters as described in Section 2. We now model the observation that voters can be influenced by other voters. Voters are assumed to regularly meet and communicate their political preferences. In light of these exchanges they reconsider their ideal positions. More 
particularly, if a voter with a certain position on a particular issue learns that there are many people having a different, but nearby position on this issue (s)he may feel attracted towards the latter position. We can identify two reasons for this. The first is that there may be a group externality in the sense that people like to join groups, for example because this gives them the possibility to identify themselves with such a group. This group externality might also arise from peer group pressure or social pressure. The environment voters are living and/or working in may pressure them into conforming to the reigning political ideas. The second reason why voters might change to another ideal position stems from the incomplete information argument presented above. If voters are not completely certain about how to evaluate the consequences of different policy platforms, they may use the sizes of social groups with similar opinions at nearby positions as information sources (as a kind of poll). This incomplete information argument seems to be particularly relevant in the case of competing political parties, where it may be difficult for individual voters to judge the merits of (the political statements of) these different parties.

To model the social interaction we assume the decision function for changing has the following general form

$$
U_{j}\left(z, \frac{n_{z}}{N}\right)
$$

that is, it depends upon the position $z$ to which the voter considers moving (given the voter's current position) and upon the relative size of the social group residing at that new position. However, voters are not likely to know the exact distribution of preferences on the issue space. It seems more reasonable to assume that voters exchange information about their ideal positions when meeting other voters and in this way obtain an informed guess of the distribution of preferences. We model this as follows. With some probability $\varepsilon \in[0,1]$, voters reconsider their political preferences (or political 'beliefs'). If this happens, voter $j$ aspires to meet $\lambda_{j}$ other voters in order to get a 'plausible' idea of the actual distribution. Because some voters are more active in meeting other voters than other voters are, we assume that the variable $\lambda_{j}$ is drawn from the discrete uniform distribution on $\{0,1,2, \ldots,\lceil\Lambda N\rceil\}$. Here $\lceil\Lambda N\rceil$ is the largest integer smaller than or equal to $\Lambda N$, with $\Lambda \in(0,1)$. For our simulations we will take $\Lambda=\frac{1}{10}$. We assume that voters are drawn in random order to meet these other people. Let $i_{1}, i_{2}, \ldots, i_{N}$ be the order of these voters, where $i_{1}$ corresponds to the first voter that is drawn. This first voter meets $\lambda_{i_{1}}$ voters randomly drawn from the population $N \backslash\left\{i_{1}\right\}$ and learns their ideal position. In turn, these other voters learn the respective voter's position. ${ }^{10}$ Now the $s^{\prime}$ th voter meets $\lambda_{i_{s}}^{*}$ other voters drawn from the population $N_{i_{s}}^{*}$, where $\lambda_{i_{s}}^{*}=\max \left\{\lambda_{i_{s}}-\#(\right.$ voters already met by voter $\left.s), 0\right\}$ and $N_{i_{s}}^{*}=N \backslash\left\{\right.$ voters already met by voter $s$ and $\left.i_{s}\right\}$. Notice that people can meet more

\footnotetext{
${ }^{10}$ An alternative way to model this would be to draw, with replacement, from the population of $N$ voters, pairs of voters who learn each others ideal point. On the other hand, we could also assume that the information transmission is unilateral, i.e. only one voter in the pair learns the ideal position of the other voter. This would resemble information transmission by opinion leaders generated in, for example, newspaper articles or talkshows on TV.
} 

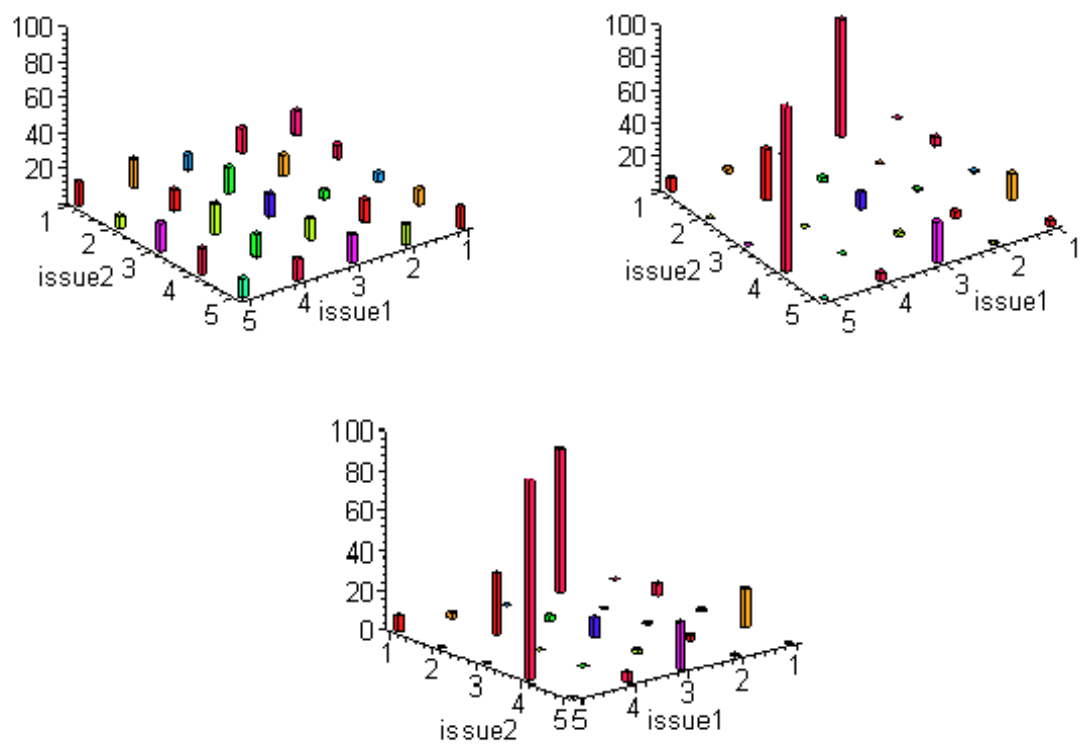

Figure 4: The evolution of the distribution of voters' ideal position over the policy space, with $\alpha=0.5$ and $\Lambda=0.1$. The height of these bars corresponds to the number of voters at each position in the: initial configuration (top left panel); the 30-th configuration (top right panel); and the 40-th configuration (bottom panel).

voters than they originally intended to. Therefore, $\lambda_{j}$ actually corresponds to a lower bound of the number of voters voter $j$ meets. Each voter now has some private information about the distribution of ideal points. In particular, if we let $N^{j}$ be the number of people voter $j$ meets and $n_{z}^{j}$ the number of people voter $j$ meets that have ideal position $z$, then $\frac{n_{z}^{j}}{N^{j}}$ serves as an estimate for $\frac{n_{z}}{N}$. Each voter uses these estimates to evaluate the positions in the issue space.

It seems reasonable to construct the above decision function $U_{j}$ by adjusting the utility function (1) discussed in Section 2 through a term that models the group externality. More specifically, for voter $j$ with ideal position $x$ the net benefit from moving to a position $y$ is described as

$$
U_{j}\left(z, \frac{n_{z}^{j}}{N^{j}}\right)=u_{j}(z)+W_{j}\left(\frac{n_{z}^{j}}{N^{j}}\right)
$$

where $W_{j}()>$.0 is the group externality function which is assumed to be nondecreasing in its argument. From (3) it is clear that there are two, partially offsetting, effects from moving to another position. The first is the negative effect of giving up one's existing belief of what is the ideal position, the second is the possibly positive 


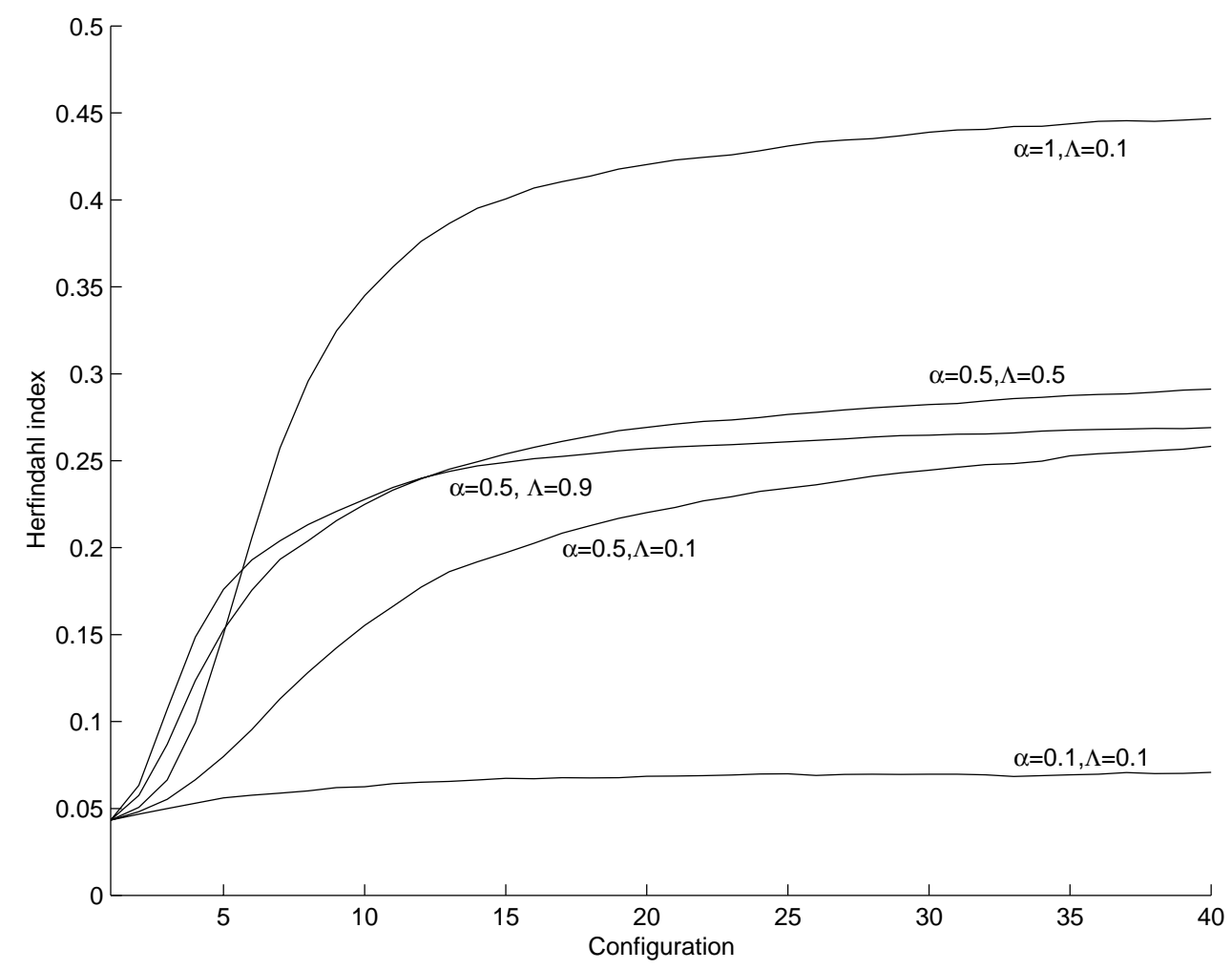

Figure 5: The evolution of the Herfindhal index over 40 updates for different values of the parameter of the individual sensitivity to group size, $\alpha$, and the parameter of information sampling size, $\Lambda$.

effect of moving to a position that is shared as an ideal point by more voters. ${ }^{11}$ This updating of beliefs (ideal positions) is assumed to take place between elections, prior to the formation of interest groups and the search procedure of the challenger. Figure 4 gives an example of the distribution of ideal points after respectively 30 and 40 updates (to be interpeted as the number of elections). The height of the bars corresponds to the number of voters at each position. Remember that the process of social interaction starts with ideal positions that are uniformly distributed over the issue space. Clearly, social interaction gives rise to clustering of opinions.

In order to analyze this clustering feature we use the following measure, known

\footnotetext{
${ }^{11}$ In our simulations we use

$$
W_{j}\left(\frac{n_{z}^{j}}{N^{j}}\right)=\alpha \ln \left(1+\frac{n_{z}^{j}}{N^{j}}\right),
$$

where $\alpha \geq 0$ measures sensitivity to group size. Modeling the group externality function this way is consistent with the theory of social impact formulated by Latane (1981). This theory has found empirical support in a number of sociological studies, such as Latane and Bourgeois (1996). The estimated value of $\alpha$ in Latane (1981) is 0.46. In our simulations we take $\alpha=0.5$.
} 
as the Herfindhal index of concentration,

$$
C=\frac{1}{N^{2}} \sum_{z} n_{z}^{2}
$$

This measure increases as the distribution of the population of voters over different positions becomes more uneven. To get some intuition for this measure notice that, for the extreme case where all voters cluster into only one position, $C$ equals 1 . On the other hand, if there is no clustering at all and the population of voters is evenly divided over all possible positions then the number of voters at every single position would be $\frac{N}{K_{1} \times \ldots \times K_{I}}$ and $C$ reduces to $\frac{1}{K_{1} \times \ldots \times K_{I}}$ (corresponding to $\frac{1}{25}=0.04$ in our simulations), which therefore constitutes a lower bound for the level of clustering. Finally, to be able to compare the values of $C$ from our simulations to the level of clustering, suppose that we find a value of this measure equal to $C=C_{0}$. This is equivalent to a situation where all voters are clustered evenly into $\frac{1}{C_{0}}$ positions. $C$ increases as the number of updates increases. For the social configuration after 40 updates, presented at Figure 4, we have $C=0.16$, which is approximately equivalent to all voters being organized evenly into 6 of the 25 positions. More information about the nature of the clustering process can be extracted from Figure 5. This figure presents the evolution of the Herfindhal index over 20 elections for different values of $\alpha$ and $\Lambda$. From this figure we conclude that $i$ ) an increase in the social impact parameter $\alpha$ leads to higher clustering for a given sample size $\Lambda$. Notice, however, that heterogeneity in opinions survives, since the clustering measure has a maximum value of around 0.45 ; ii) the lower the sample size parameter $\Lambda$, the longer it takes for the system to cluster; and iii) for a given value of the social impact parameter $\alpha$, there seems to be no monotonic relation between the clustering measure $C$ and the sample size parameter $\Lambda$. One effect of a high value of $\Lambda$ is that it increases the predictability of the social dynamics. Given the initial uniform distribution of ideal points and strengths, if some voters potentially sample almost the whole population of voters $(\Lambda=90 \%)$ the system will typically cluster at those positions that are most crowded according to this initial distribution of voters in the issue space. In that case, clustering will largely depend on the initial representation of positions among the voters. For low values of $\Lambda$, voters are not well informed and their estimates of the distribution of political preferences may very well be biased. Chance is then an important determinant of the emergence of new clusters.

Having explained the clustering procedure, we now consider what happens in our model if we allow for this kind of social dynamics. Let us prohibit the formation of interest groups for the moment. Convergence to the center, separation between party platforms and frequency of election victories for the challenger are all shown in Figure 6 for 2 and 8 polls per election, respectively.

From these graphs we see that, for the first couple of elections, when the process of clustering has not fully matured yet, the policy outcome converges to the center and the separation between party platforms decreases. These results are similar to 

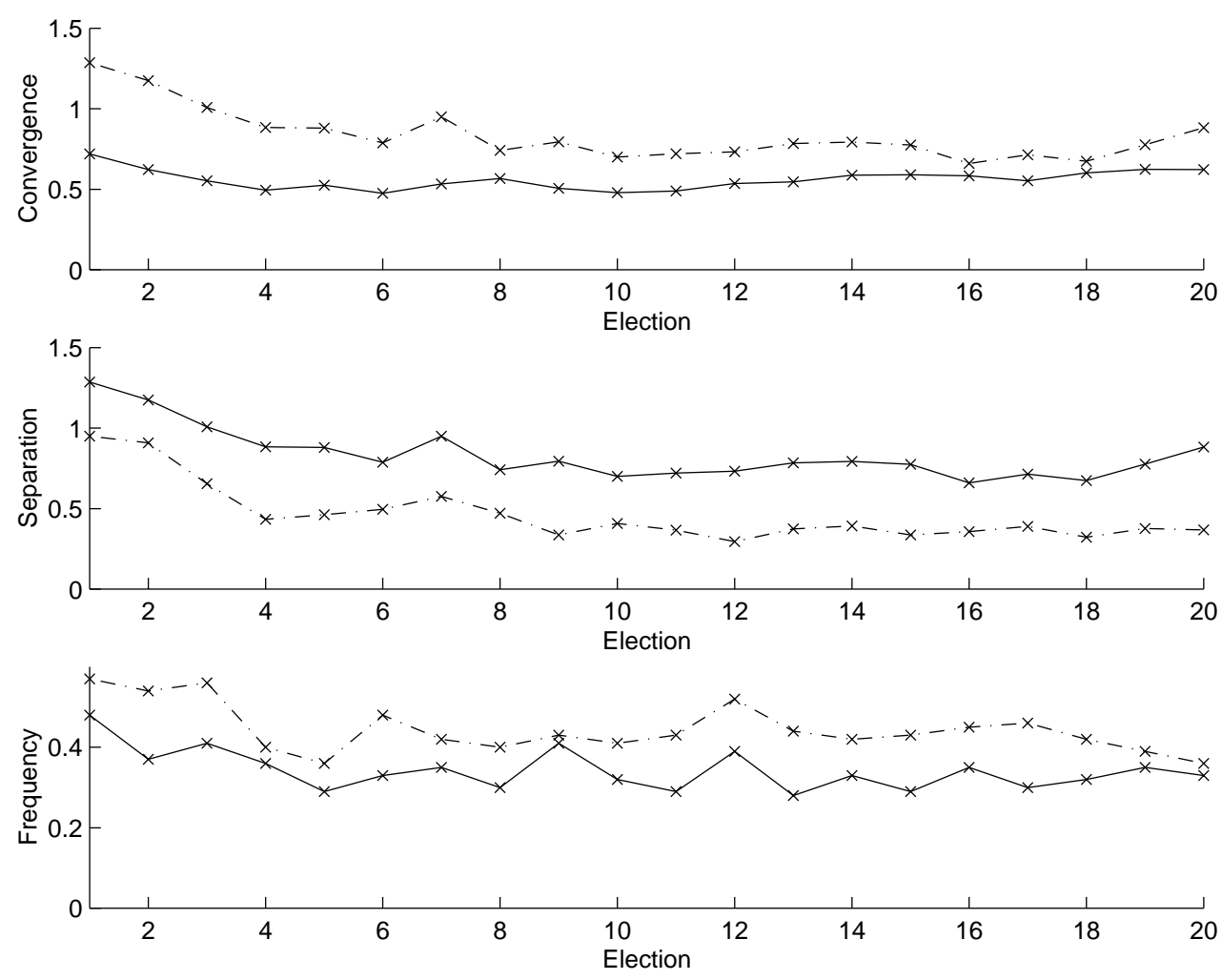

Figure 6: Time series of different measures, averaged over 100 trials, for the social interaction model. Solid lines correspond to the model with 8 polls, broken lines correspond to 2 polls. Upper panel: average Euclidean distance between center and election outcome. Middle panel: average Euclidean distance between challenger and incumbent. Lower panel: frequencies with which the challenger wins an election.

the ones found with the basic model (compare Figure 1). The social clusters that have appeared are only moderate in size and hence do not break the symmetry of the distribution of voter preferences. However, as time goes by clustering increases and the symmetry of the distribution of voter preferences is broken. As can be seen from Figure 6 eventually there seems to be a slight increase in the different distance measures. The most notable effect of the social dynamics therefore seems to be that it prohibits (also in the long run) party platforms to converge to each other or to the center of the distribution.

\section{The full model}

Now that we have separately introduced social clustering and interest group formation in our spatial competition framework, we are ready to study the characteristics of the 
full model. First observe that whereas social clustering is a long run process that depends only on its own past, the interest group formation process also depends on the social clustering and election outcomes. The sequence of events of the full model is as follows:

Step 1. Voters ideal positions and issue weights (strengths) are randomly drawn from a uniform distribution.

Step 2. Interest groups develop and become effective as in Section 3.

Step 3. The challenger runs polls and selects its policy platform for the upcoming election as described in Section 3.

Step 4. The election is run and the party that wins the election becomes the new incumbent and implements its platform.

Step 5. Social interaction takes place as described in Section 4, leading to a new configuration of voter preferences.

Step 6. The sequence of events restarts at Step 2.

The results of the simulations for the full model are shown, together with the simulation results for the models from Sections 2, 3 and 4, in Figure 7. The upper left panel of Figure 7 shows the average distance (over 100 trial runs again) between the incumbent and the center of the distribution. Clearly, this distance is smallest for the basic model and highest for the full model. Furthermore, in the early elections (say the first 5) this difference can be attributed mainly to the effect of the interest groups. Later on, however, the social dynamics as well as the existence of the interest groups seem to be responsible for the difference. In fact, over time the effect of the interest groups decreases whereas the effect of the social dynamics increases. The latter effect ensures that there is no apparent convergence in the full model. The reason should be clear by now: in the long run the clustering of political preferences really becomes significant and the appearance of large clusters drives the policy outcome away from the center of the distribution, which is moving as well.

The upper right panel of Figure 7 shows the average separation between the policy platforms of the two parties. Clearly, this separation is much larger for the full model and the model with interest groups than for the basic model and the model with social clustering. The existence of interest groups therefore seems to play an important role in explaining the separation between political parties.

Similarly, the probability for the challenger of winning an election is significantly larger when interest groups are allowed to form, as can be seen from the lower left panel of Figure 7. There is also a positive effect of social clustering on the winning probability for the challenger, but this effect is clearly smaller. The probability of winning is influenced by the existence of interest groups via two channels. First, since 

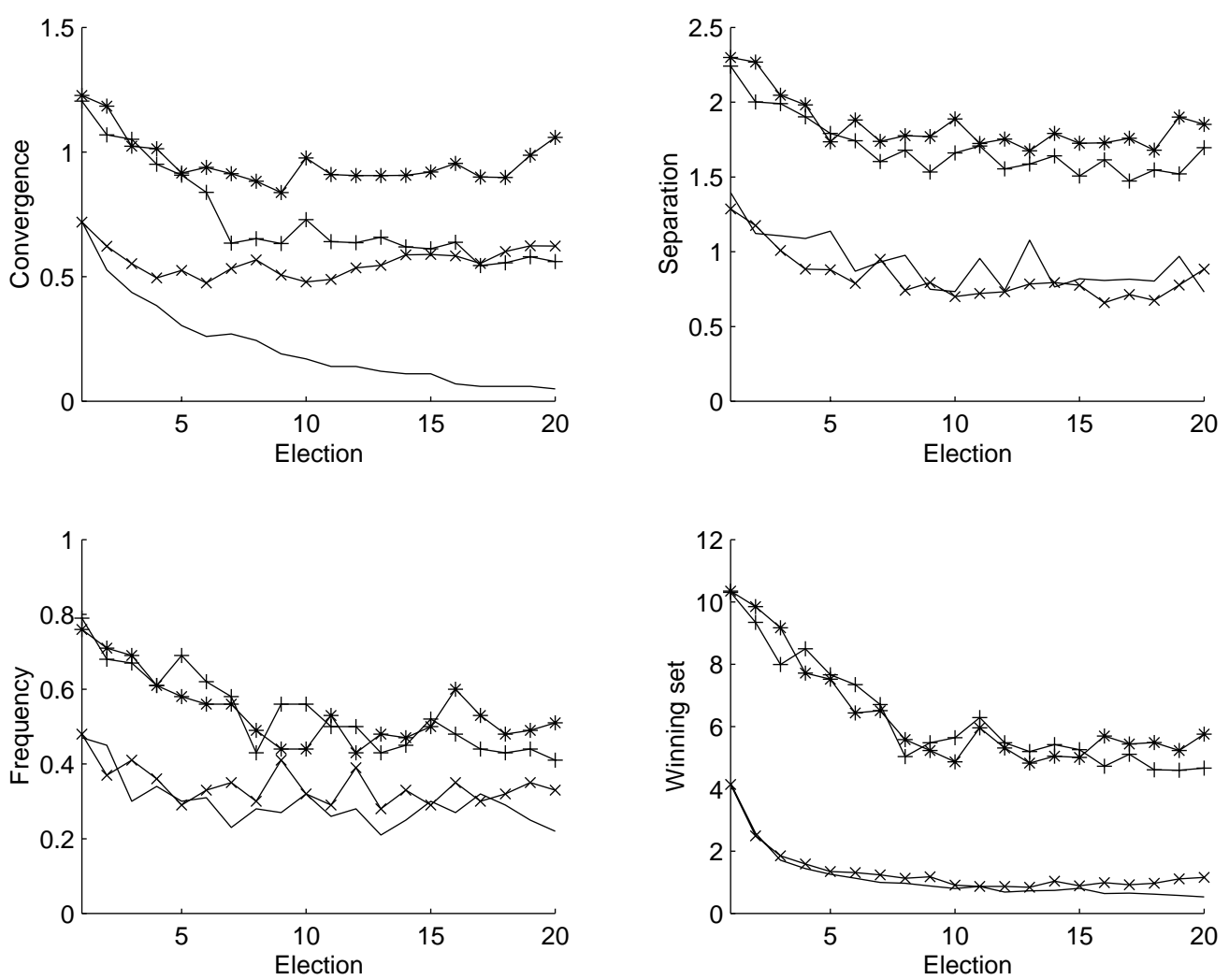

Figure 7: Time series of different measures, averaged over 100 trials, for the four different models (benchmark model: -, interest group model: +, social interaction model: $\times$, full model: $*$ ). Upper left panel: average Euclidean distance between center and election outcome. Upper right panel: average Euclidean distance between challenger and incumbent. Lower left panel: frequencies with which the challenger wins an election. Lower right panel: size of the winning set.

interest groups enable the challenger to run more polls which generate additional information about the electoral landscape, it is easier for the challenger to find an element of the winning set. This is a transient effect, however, since it will also speed up the process of convergence towards the center of the distribution. Second, the coordination of voting behavior induced by the interest groups changes the electoral landscape and increases the size of the winning set, given the incumbent's position. This is illustrated by the lower right panel of Figure 7 where the average number of winning points for the challenger is given. The presence of interest groups clearly leads to a sizable increase in the number of winning points, as has been formally shown in a similar environment by Sadiraj et al. (2004b) and this is what drives most of the results found in this simulation study. 


\section{Concluding remarks}

Kollman et al. (1992) extended the Downs-Hotelling spatial model of electoral competition in an important way by having political parties poll for gaining more information about the preferences of voters, acknowledging the huge informational problems parties are confronted with in determining optimal platforms. In this paper we have investigated the consequences of adding two realistic phenomena: $i$ ) the formation of interest groups as information brokers between voters and parties, and ii) social interaction affecting the political preferences of voters that are typically badly informed as to how their concerns are precisely affected by policies. To model these phenomena, psychological findings (particularly, dissatisfaction and identification as motivational forces) were used as explanatory factors.

Our model not only allows for the endogenous formation of interest groups, it also focuses on a neglected channel of information transmission by such groups, which concerns the provision of resources to candidates for polling. As a consequence, our model naturally integrates the two motives distinguished in the literature for political contributions: the electoral support motive and the influence motive. The latter motive is integrated through the fact that the provision of resources for polling is conditioned by the political stance of the interest group.

The simulation results, first of all, corroborate Kollman et al.'s finding of no 'chaos'. In the basic model there is a clear movement towards the center of the distribution of voters' preferences. This changes, however, in the presence of interest groups. Moreover, we see a divergence of party platforms, even though parties are office seeking. This is related to the finding that interest groups enlarge the winning set, thereby increasing the probability for the challenger to win the election.

We now turn to some social welfare consequences of our model. First, interest groups as information brokers can be beneficial because winning platforms, if they exist, are faster selected. This is particularly helpful if political preferences are no longer fixed, as in case of the model with social clustering. In the longer run the welfare consequences of the model with interest groups are less favorable, however. Notice that with voters' ideal points and issue weights being drawn from a uniform distribution, convergence to the center would maximize expected (utilitarian) social welfare. Since convergence is weaker with interest groups, where more volatility is observed, expected social welfare is negatively affected in that case. On the other hand, the fact that, with interest groups, voters with ideal points different from the center get sometimes served in terms of policy might be seen as a separate element of social welfare. A complicating factor in welfare comparisons is that it might be the case (see e.g. Morton (1993)) that people like winning elections, independent of the policy outcome.

The framework presented in this paper is seen as a starting point for a more realistic analysis of the interaction between voters and parties. More realistic, in the sense of taking more seriously the severe information problems these agents are confronted 
with as well as the strong evidence from psychology and behavioral economics that individuals are cognitively much less sophisticated (and also more emotional) than assumed in game theory. As shown in this paper, this also leads to a natural and important role for interest groups as information brokers. For future research we think it is important to further study this role of interest groups. Another topic deserving closer scrutiny concerns the belief formation process of voters. Interesting extensions of our model of social clustering, based on imitation, concern the role of the media and of (other) opinion leaders. From a theoretical angle it would be interesting, for example, to establish a more rigorous underpinning of the enlargement of the winning set that we observed in case of interest groups, which is related to the coordination of voting that they induce (see Sadiraj et al. (2004b)). How do interest groups as information brokers affect the 'chaos' and 'cycling' results that play such a prominent role in the theoretical literature on spatial voting? Finally, predictions derived from the models might be testable against empirical data, such as the prediction that greater political volatility will emerge when identification with interest groups becomes stronger.

\section{References}

[1] Akerlof, G.A and R.E. Kranton (2002): Economics and identity. Quarterly Journal of Economics 115, 715-753.

[2] Ansolobehere, S., J.M. de Figueiredo And J.M. Snyder (2002): Why is there so little money in U.S. politics? NBER Working Paper 9409.

[3] Banerjee, A.V. (1992): A simple model of herd behavior. Quarterly Journal of Economics 61, 29-56.

[4] Bikhchandani, S., D. Hirshleifer And I. Welch (1992): A theory of fads, fashion, custom, and cultural change as informational cascades. Journal of Political Economy 100, 992-1026.

[5] Camerer, C.F. (2002): Behavioral Game Theory: Experiments on Strategic Interaction, Princeton: Princeton University Press.

[6] Corradi, V. and A. Ianni (1998): Consensus and co-existence in an interactive process of opinion formation. CARESS Working Paper 98-09. University of Pennsylvania.

[7] Coughlin, P.J. (1990): Majority rule and election models. Journal of Economic Surveys 4, 157-188.

[8] De Marchi, S. (2003): A computational model of voter sophistication, ideology, and candidate position taking. In: K. Kollman, J.H. Miller, and S.E. Page (eds.), Computational Models in Political Economy, Cambridge, MA: MIT Press. 
[9] Grossman, G.M. and E. Helpman (1999): Competing for endorsements. American Economic Review 89, 501-524.

[10] Hinich, M.J. And M.C. Munger (1997): Analytical Politics. Cambridge: Cambridge University Press.

[11] JaCkson, J.E. (2003): A computational theory of electoral competition. In: K. Kollman, J.H. Miller, and S.E. Page (eds.), Computational Models in Political Economy, Cambridge, Massachusetts: MIT Press.

[12] Kirman, A.P. (1993): Ants, rationality and recruitment. Quarterly Journal of Economics 108, 137-156.

[13] Kollman, K., J.H. Miller And S.E. Page (1992): Adaptive parties in spatial elections. American Political Science Review 86, 929-937.

[14] Kollman, K., J.H. Miller and S.E. Page (1998): Political parties and electoral landscapes. British Journal of Political Science 28, 139-158.

[15] Latane, B. (1981): The psychology of social impact. American Psychologist 36, 343-356.

[16] Latane, B. And M.J. Bourgeois (1996): Experimental evidence for dynamic social impact: The emergence of subcultures in electronic groups. Journal of Communication 46, 35-47.

[17] Marcus, G.E. And M.B. MacKeun (1993): Anxiety, enthusiasm, and the vote - the emotional underpinning of learning and involvement during presidential campaigns. American Political Science Review 87, 672-685.

[18] Morton. R.B. (1993): Incomplete information and ideological explanations of platform divergence. American Political Science Review 87, 382-392.

[19] Mueller, D.C. (2003): Public Choice III, Cambridge: Cambridge University Press.

[20] Poole, K.T. And H. Rosenthal (1991): Patterns of congressional voting. American Journal of Political Science 35, 228-278.

[21] Ross, S.M. (1993): Introduction to Probability Models, San Diego: Academic Press

[22] Sadiraj, V., J. Tuinstra and F. Van Winden (2004a): Interest group size dynamics and policymaking. CeNDEF Working Paper 04-06, University of Amsterdam, forthcoming in Public Choice. 
[23] Sadiraj, V., J. Tuinstra And F. van Winden (2004b): On the size of the winning set in the presence of interest groups. Working Paper, University of Amsterdam. 